\title{
Early and late effects of the DPP-4 inhibitor vildagliptin in a rat model of post-myocardial infarction heart failure
}

Meimei Yin, Herman HW Silljé, Maxi Meissner, Wiek H van Gilst and Rudolf A de Boer

\begin{abstract}
Background: Progressive remodeling after myocardial infarction (MI) is a leading cause of morbidity and mortality. Recently, glucagon-like peptide (GLP)-1 was shown to have cardioprotective effects, but treatment with GLP-1 is limited by its short half-life. It is rapidly degraded by the enzyme dipeptidyl peptidase-4 (DPP-4), an enzyme which inhibits GLP-1 activity. We hypothesized that the DPP-4 inhibitor vildagliptin will increase levels of GLP-1 and may exert protective effects on cardiac function after MI.
\end{abstract}

Methods: Sprague-Dawley rats were either subjected to coronary ligation to induce MI and left ventricular (LV) remodeling, or sham operation. Parts of the rats with an Ml were pre-treated for 2 days with the DPP-4 inhibitor vildagliptin (MI-Vildagliptin immediate, MI-VI, $15 \mathrm{mg} / \mathrm{kg} /$ day). The remainder of the rats was, three weeks after coronary artery ligation, subjected to treatment with DPP-4 inhibitor vildagliptin (MI-Vildagliptin Late, MI-VL) or control (MI). At 12 weeks, echocardiography and invasive hemodynamics were measured and molecular analysis and immunohistochemistry were performed.

Results: Vildagliptin inhibited the DPP-4 enzymatic activity by almost $70 \%$ and increased active GLP-1 levels by about 3 -fold in plasma in both treated groups ( $p<0.05$ vs. non-treated groups). Cardiac function (ejection fraction) was decreased in all $3 \mathrm{Ml}$ groups compared with Sham group $(p<0.05)$; treatment with vildagliptin, either early or late, did not reverse cardiac remodeling. ANP (atrial natriuretic peptide) and BNP (brain natriuretic peptide) mRNA levels were significantly increased in all $3 \mathrm{Ml}$ groups, but no significant reductions were observed in both vildagliptin groups. Vildagliptin also did not change cardiomyocyte size or capillary density after MI. No effects were detected on glucose level and body weight in the post-MI remodeling model.

Conclusion: Vildagliptin increases the active GLP-1 level via inhibition of DPP-4, but it has no substantial protective effects on cardiac function in this well established long-term post-MI cardiac remodeling model.

Keywords: vildagliptin, myocardial infarction, cardiac remodeling, heart failure, diabetes

\section{Introduction}

Glucagon-like peptide-1(GLP-1; 7-36 amide), which belongs to the proglucagon family of incretin peptides, is secreted by enteroendocrine $\mathrm{L}$ cells of the intestinal mucosa and released in response to food intake [1]. GLP-1 analogues have been used for the clinical treatment of type 2 diabetes because of its multiple actions on pancreatic function [2-4]. Besides its effects on glucose metabolism, GLP-1 has been proven to exert

\footnotetext{
* Correspondence: r.a.de.boer@umcg.nl

University Medical Center Groningen, University of Groningen, Department of Cardiology, Groningen, The Netherlands
}

cardiovascular effects in clinical and experimental studies, in the presence or absence of diabetes [5].

GLP-1 receptors (GLP-1R) are expressed in rodent and human heart and vasculature [6-8]. GLP-1R deficient mice exhibit increased left ventricular (LV) thickness, impaired LV contractility and LV diastolic function compared with control mice [9]. However, whether the beneficial effects of GLP-1 on the heart are conferred through direct GLP-1R signaling or indirect, through the GLP-1R-dependent improvement in glucose metabolism is not well established. Administration of GLP-1 improves myocardial function and 
cardiac output in experimental models of cardiac injury or heart failure. GLP-1 increased cardiac output, and reduced LV end diastolic pressure, in association with improved myocardial insulin sensitivity and myocardial glucose uptake in dogs with rapid pacinginduced congestive heart failure [10]. Consistent with the cytoprotective action of GLP-1 in the endocrine pancreas, GLP-1 reduced infarct size in the isolated perfused rat heart and in animal models of myocardial ischemia [11-13]. A 72 hours infusion of GLP-1 in patients with acute myocardial infarction (MI) and an LV ejection fraction (LVEF) less than $40 \%$ resulted in significantly improved LVEF and improved regional and global wall motion scores, in association with a trend towards earlier hospital discharge [14]. In a pilot study of both diabetic and non-diabetic subjects with heart failure, an improved LV function was observed following a 5 week continuous infusion of GLP-1(7-36) [5].

However, active GLP-1 in the circulation is rapidly (within two minutes) degraded by dipeptidyl peptidase-4 (DPP-4) [15]. An alternative approach for enhancing GLP-1 action involves the use of DPP-4 inhibitors. The DPP-4 inhibitor sitagliptin [16] and saxagliptin [17] have been approved for type 2 diabetic patients. Vildagliptin is only approved and used in Europe [18].

The studies on cardiovascular effects of GLP-1, discussed above, have consequently assessed only shortterm improvements in cardiac performance, like in postischemic or cardiomyopathy states. There are no reports on long-term effects of DPP-4 inhibition in a post-MI cardiac remodeling model. Furthermore, the actions of DPP-4 inhibitors on cardiac remodeling after MI are incompletely understood. We hypothesized that the DPP-4 inhibitor vildagliptin may exert beneficial effects on infarcted hearts by inhibiting the degradation of active GLP-1 and other cardiovascular peptides. The purpose of our study was therefore to determine whether vildagliptin has beneficial effects on long-term post-MI remodeling in rats and to explore the mechanisms underpinning these effects.

\section{Methods and materials Animals}

Male Sprague-Dawley rats (Harlan, Zeist, The Netherlands) weighing 250-260 g were housed in groups of 4-5 on a 12-hour light-dark cycle with standard rat chow and water available ad libitum. The animals were subjected to sham-surgery or left coronary artery ligation. All experiments were carried out after approval of the Animal Ethical Committee of the University of Groningen for the use of experimental animals and conform to the Guide for Care and Use of Laboratory Animals.

\section{Drugs}

The DPP-4 inhibitor vildagliptin was kindly supplied by Novartis, The Netherlands. Vildagliptin was dissolved in the drinking water and administered in a final concentration of $15 \mathrm{mg} / \mathrm{kg} / \mathrm{day}$, which is chosen according to the previous studies $[19,20]$.

\section{Experimental protocol}

Rats were randomly subjected to induction of MI or sham surgery. Briefly, animals were intubated and mechanically ventilated with $2.5 \%$ isoflurane in room air enriched with $1.0 \mathrm{~L} / \mathrm{min}$ oxygen. After left-sided thoracotomy, MI was induced by ligating the proximal portion of the left coronary artery. In sham-operated rats, the same surgery was performed without ligating the suture. Parts of the rats with MI were pre-treated for 2 days with vildagliptin (MI-Vildagliptin immediate, MIVI). The remainder of the rats was, three weeks after coronary artery ligation, subjected to treatment with DPP-4 inhibitor vildagliptin (MI-Vildagliptin Late, MI$\mathrm{VL}$ ) or control (MI). At week 12, cardiac function was determined by echocardiography. After 12 weeks, rats were anaesthetized and hemodynamic function was measured invasively; thereafter blood was drawn (either anticoagulated with EDTA, or left to clot for serum) and the hearts were rapidly excised. Myocardial tissue was sectioned transversally and processed for immunohistochemistry or snap-frozen for molecular analysis.

\section{Echocardiographic measurements}

Cardiac function was assessed by echocardiography by a Vivid 7 (GE Healthcare) equipped with a $10-\mathrm{MHz}$ phase array linear transducer. The echocardiographic measurements were performed under general anaesthesia with $2.5 \%$ isoflurane, by a researcher blinded for the treatment allocation. Both 2-dimensional (2D) images in parasternal long-axis and short-axis view and 2-D guided M-mode tracings were obtained. Short-axis views were recorded at the level of mid-papillary muscles. LV internal dimensions in diastole and systole (LVIDd and LVIDs) were measured using M-mode and calculated from three cardiac cycles. LV fractional shortening (FS \%) was calculated as follows: FS = (LVIDd-LVIDs)/ LVIDd $\times 100 \%$. LV ejection fraction (EF \%) was calculated using the Teichholz method.

\section{Hemodynamic measurements}

At sacrifice, rats were anesthetized and a micro-tip pressure transducer (Millar Instr. Inc., Houston, TX, USA) was inserted into the right carotid artery. Arterial systolic and diastolic blood pressures (SBP, DBP) were recorded in the aortic arch. The catheter was advanced into the LV cavity. After a 5-min period of stabilization, heart rate (HR), LV systolic pressure (LVSP), LV end- 
diastolic pressure (LVEDP), and developed LV pressure $($ dLVP $=$ LVSP-LVEDP $)$ were measured. For indices of contractility and relaxation, the maximal rates of increase and decrease in LVP $d p / d t \max$ and $d p / d t \min$ were determined.

\section{Procurement of heart tissue and infarct size measurement}

After the rats were euthanized, hearts were rapidly excised and arrested in diastole in $2 \mathrm{M}$ ice-cold $\mathrm{KCl}$. The total heart was weighed (heart weight, HW). The right ventricle and atria were removed, and the left ventricle was weighed (left ventricular weight, LVW). The basal and apical parts of the LV were snap-frozen in liquid nitrogen. A mid-papillary slice of the LV was fixed in $4 \%$ paraformaldehyde overnight and paraffinembedded. Paraffin blocks were sectioned, and slides were dehydrated. The $5 \mu \mathrm{m}$ sections were stained with picrosirius red/fast green [21]. The infarct size was calculated as percentage of the scar length to the total LV circumference. The images were obtained with a Leica microscope and analyzed using appropriate software (Image-pro plus, version 4.5.0.29).

\section{Biomolecular assays}

EDTA plasma was used to measure active GLP-1 and DPP-4 activity, using a commercial Enzyme Linked Immunosorbent Assay, according to the guidelines provided by the manufacturer (Quantikine, R\&D system, London, UK). Glucose levels were measured with a blood glucose monitor (Accu-Check ${ }^{\circledR}$, Roche, Germany). Plasma triglyceride and cholesterol levels were determined using commercially available kits (Roche Diagnostics, Mannheim, Germany and DiaSys Diagnostic Systerms, Holzheim, Germany).

\section{Capillary density}

To visualize the capillaries in the myocardium, endothelial cells were stained with Lection GSI (Sigma-Aldrich Chemie, Zwijndrecht, The Netherlands), as previously described [22]. Briefly, $5-\mu \mathrm{m}$ sections were deparaffinised and rehydrated and endogenous peroxidase was inhibited by methanol $/ \mathrm{H}_{2} \mathrm{O}_{2}(0.3 \%)$ for 15 minutes. Sections were incubated overnight with biotinylated Lectin GSI (1:100) at room temperature. Then, in a second step, the signal was intensified with an $\mathrm{ABC}$-complex containing peroxidase labeled biotins (1:100) (Lab vision, CA, USA). Finally, the sections were incubated with a $\mathrm{Ni}$-Co amplified DAB solution to which a stable peroxide substrate buffer was added (Pierce, CA, USA). Endothelial cells of capillaries and larger vessels were visualized in the myocardium as a brown precipitate. A background staining was not used in order to avoid interference with the Lectin staining. Capillary density in the viable LV wall was calculated as the number of capillaries per tissue area.

\section{Left ventricular hypertrophy}

First, left ventricular hypertrophy was expressed as the ratio of left ventricular weight to body weight. Microscopically, left ventricles were cut into $5 \mu \mathrm{m}$ transversal slices from apex to base. Afterwards, sections were stained with a Gomori's silver staining in order to visualize the membrane of the cardiomyocytes, as described previously [21]. Cardiomyocyte size was measured transversally cut in the border zone of the infarcted area using image analysis (Zeiss KS400, Germany).

\section{Real-time PCR}

We used myocardial tissue (of border zone of the infarction) to extract total RNA with TRIzol reagent (Invitrogen Corp., Carlsbad, CA, USA). The nano-drop device was used to quantify the RNA concentration. First strand cDNA was synthesized by reverse transcription reaction by using random primer mix, and used as a template to amplify genes of interest; for this specific primers against ANP (atrial natriuretic peptide), BNP (brain natriuretic peptide), collagen I, MMP-9 (matrix metalloproteinase-9) were designed. All gene expression values were normalized to 36B4 mRNA levels.

\section{Data analysis}

All data are presented as means \pm standard errors of the mean (sem). Data of infarcted rats were only included if the infarction comprised the major part of the LV free wall, since small infarctions $(<20 \%)$ are found to be hemodynamic fully compensated (two animals were excluded from the MI group, and three animals were excluded from each vildagliptin-treated groups MI-VI and MI-VL). Statistical analysis among groups was performed by one-way analysis of variance (ANOVA) followed by Tukey post-hoc test. Within-group comparisons between week 3 and week 12 were analyzed by Paired-Sample T-Test. Differences were considered statistically significant if $\mathrm{p}<0.05$.

\section{Results}

\section{Active GLP-1, DPP-4 activity and glucose levels}

We measured the DPP-4 activity and active GLP-1 levels in plasma after 12 weeks of vildagliptin treatment to confirm that continuous administration of vildagliptin (supplied at $15 \mathrm{mg} / \mathrm{kg}$ in the drinking water) was indeed associated with suppression of plasma DPP-4 activity, and increase in the active GLP-1 levels. Plasma DPP-4 activity was significantly reduced by almost $70 \%$ in both treatment groups compared to non-treated groups. This was associated with a significant increase of active GLP1 level in both vildagliptin groups (Figure 1).

During the 12 weeks of follow up, we measured glucose levels at baseline, week 6 and week 12. No significant changes in glucose levels were observed, suggesting 


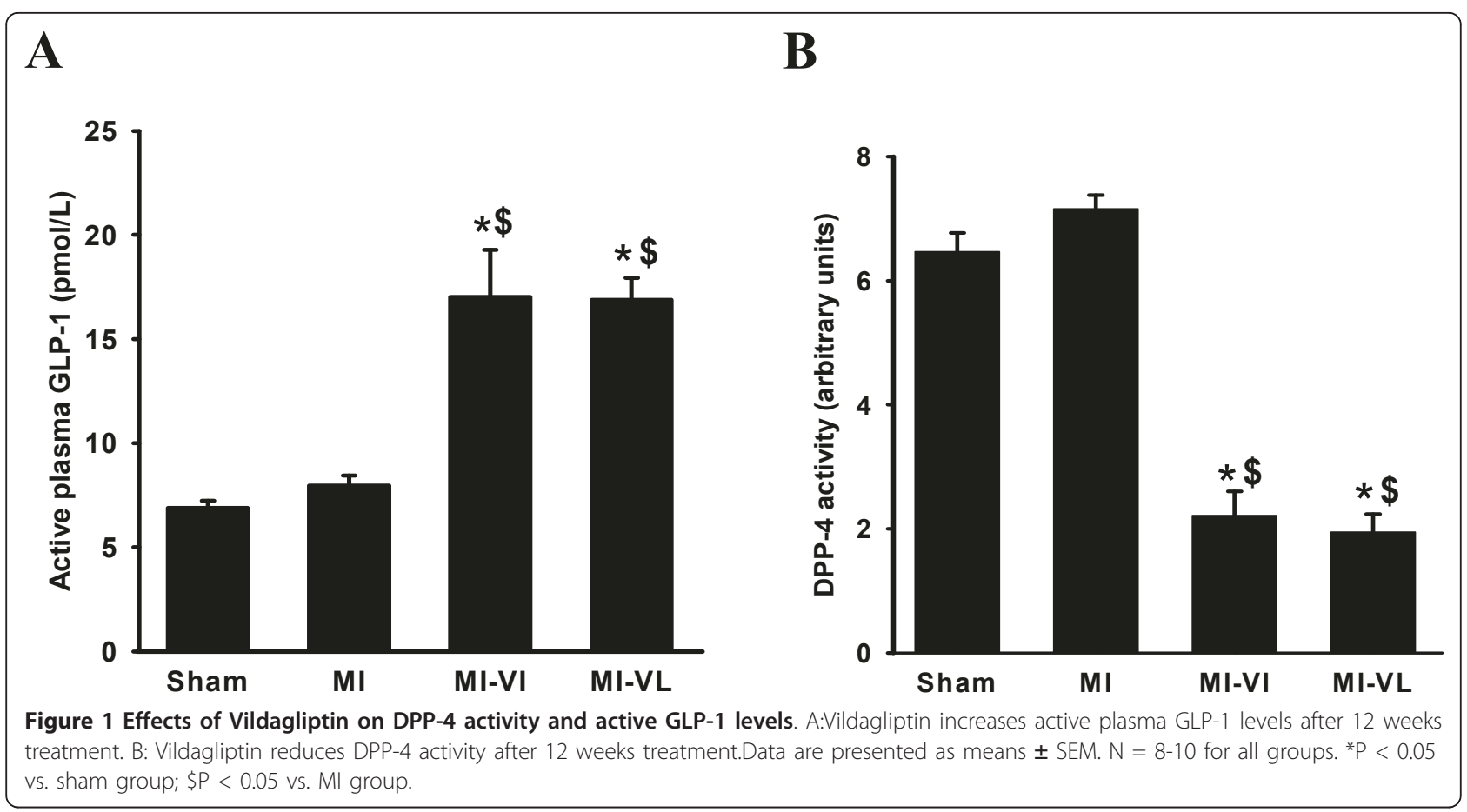

that vildagliptin has no effect on normal glucose levels. The similar findings were observed in plasma cholesterol and triglycerides that no significant differences were found among all groups (Table 1B).

\section{Body Weight, LV weight, and infarct Size}

Body weight (BW), LV weight (LVW) to body weight ratios (LVW/BW) and infarct sizes are shown in Table 1A. Ligation of the left coronary artery resulted in an infarct size of $47 \pm 2 \%$ in control-treated MI group (Figure $2 \mathrm{~B})$. Although there was no significant reduction in the infarct size, vildagliptin treatment (both immediate and late) was associated with a trend towards smaller infarct size over the 3-month period of treatment compared with the MI control group (Figure 2B). There was no difference in body weight between groups both at baseline and at 12 weeks after MI surgery. The LVW/ $\mathrm{BW}$ ratios in all MI groups were significantly increased compared to LVW/BW of the sham-operated group, however, LV hypertrophy was not significantly reduced by vildagliptin treatment (both groups) compared to MI control (Table 1A).

Table 1 Characteristics of the experimental groups at sacrifice (12 weeks).

\begin{tabular}{|c|c|c|c|c|c|}
\hline & & $\begin{array}{l}\text { Sham } \\
N=8\end{array}$ & $\begin{array}{c}\mathrm{MI} \\
\mathrm{N}=10\end{array}$ & $\begin{array}{l}\mathrm{MI}-\mathrm{VI} \\
\mathrm{N}=9\end{array}$ & $\begin{array}{l}\mathrm{MI}-\mathrm{VL} \\
\mathrm{N}=9\end{array}$ \\
\hline \multirow[t]{4}{*}{ A } & $\begin{array}{l}\text { BW (g) } \\
\text { (baseline) }\end{array}$ & $321 \pm 9$ & $313 \pm 5$ & $321 \pm 2$ & $306 \pm 4$ \\
\hline & $\begin{array}{l}\text { BW }(\mathrm{g}) \\
(12 \text { week) }\end{array}$ & $446 \pm 15$ & $449 \pm 11$ & $436 \pm 5$ & $450 \pm 7$ \\
\hline & $\begin{array}{l}\text { LWW (g) } \\
\text { (12 week) }\end{array}$ & $0.93 \pm 0.03$ & $1.05 \pm 0.03^{*}$ & $0.97 \pm 0.02$ & $1.08 \pm 0.03^{*}$ \\
\hline & LVW/BW & $2.00 \pm 0.05$ & $2.34 \pm 0.09^{* *}$ & $2.22 \pm 0.05$ & $2.39 \pm 0.05^{* *}$ \\
\hline \multirow[t]{5}{*}{ B } & $\begin{array}{l}\text { Glucose }(\mathrm{mmol} / \mathrm{L}) \\
\text { (3 week) }\end{array}$ & $9.0 \pm 0.6$ & $8.0 \pm 0.5$ & $7.8 \pm 0.3$ & $9.5 \pm 0.4$ \\
\hline & $\begin{array}{l}\text { Glucose (mmol/L) } \\
\text { (6 week) }\end{array}$ & $7.2 \pm 0.2$ & $7.3 \pm 0.3$ & $7.1 \pm 0.1$ & $7.7 \pm 0.2$ \\
\hline & $\begin{array}{l}\text { Glucose (mmol/L) } \\
\text { (12 week) }\end{array}$ & $8.0 \pm 0.3$ & $7.3 \pm 0.2$ & $8.0 \pm 0.3$ & $7.6 \pm 0.2$ \\
\hline & Cholesterol (mmol/L) & $1.49 \pm 0.09$ & $1.48 \pm 0.04$ & $1.45 \pm 0.08$ & $1.39 \pm 0.07$ \\
\hline & Triglycerides (mmol/L) & $0.95 \pm 0.19$ & $1.12 \pm 0.13$ & $0.84 \pm 0.11$ & $0.86 \pm 0.12$ \\
\hline
\end{tabular}

Data are presented as means \pm SEM; $\mathrm{N}$ indicates number of animals; BW, body weight; LVW, left ventricle weight; LVW/BW, left ventricle weight/body weight ratio. ${ }^{* * P}<0.01$ vs. Sham. ${ }^{*} P<0.05$ vs. Sham. 
A
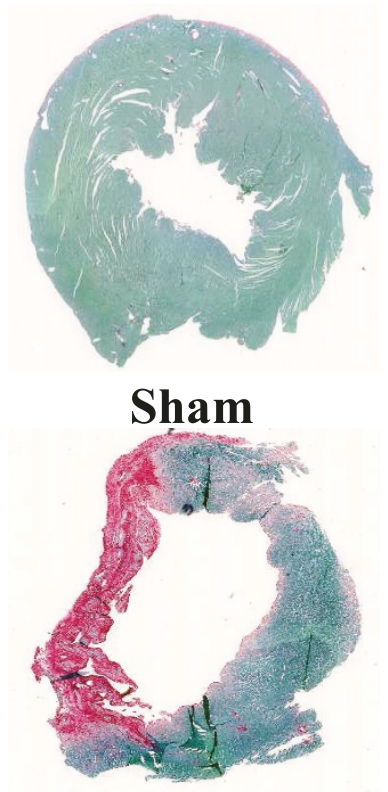

MI-VI
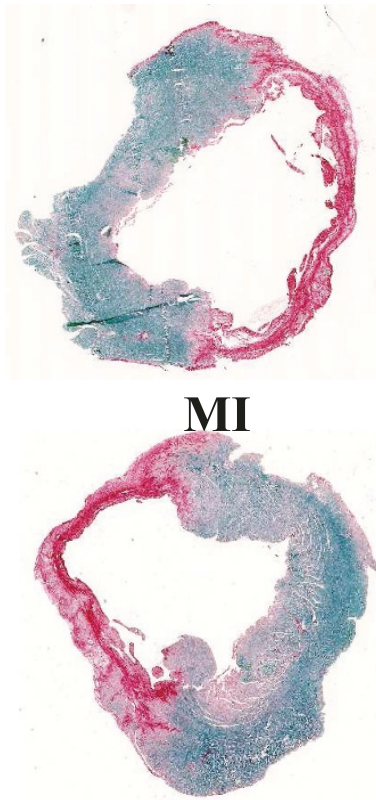

MI-VL
B

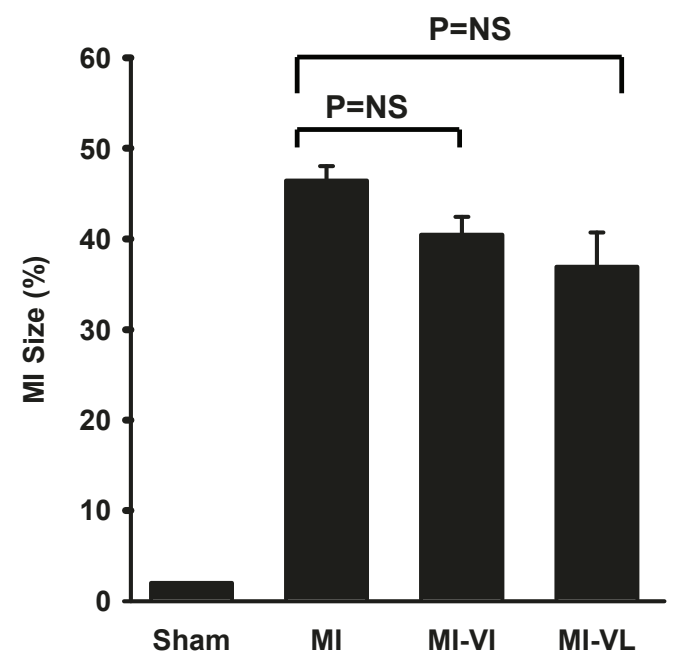

Figure 2 Effects of Vildagliptin on infarct size. A: Sirius red and fast green staining of rat myocardium shows the infarcted area with the red color in all groups. B:Graphic representation of infarct size expressed as percentage of the scar length to the total LV circumference. Data are presented as means \pm SEM. $N=8-10$ for all groups

\section{LV hemodynamic and echocardiographic parameters}

All MI rats showed evidence of heart failure, including development of LV dilatation and LV systolic dysfunction at both 3 weeks and 12 weeks after MI. Three weeks after MI, there was a significant decrease in all MI groups in FS and LVEF compared with the shamoperated group, as well as an enlarged chamber size (LVID) and a thinner wall thickness (IVS) in both systole and diastole (Table 2). During the following 9 weeks, a continued LV chamber enlargement and interventricular septum wall thinning was observed in all MI groups compared with the sham group. Although most echocardiographic parameters were not significantly different between the MI control group and the vildagliptin-treated groups, comparisons between 3 weeks and 12 weeks echocardiographic studies demonstrated that the progressive LV dilatation and wall thinning in the MI control group was

Table 2 Echocardiographic parameters of the experimental groups at week 3 and week 12.

\begin{tabular}{|c|c|c|c|c|c|c|c|c|}
\hline & \multicolumn{4}{|c|}{ Week 3} & \multicolumn{4}{|c|}{ Week 12} \\
\hline & Sham & MI & $\mathrm{MI}+\mathrm{VI}$ & $\mathrm{MI}+\mathrm{VL}$ & Sham & MI & $\mathrm{MI}+\mathrm{VI}$ & $\mathrm{MI}+\mathrm{VL}$ \\
\hline & $N=8$ & $N=10$ & $N=9$ & $N=9$ & $N=8$ & $N=10$ & $N=9$ & $N=9$ \\
\hline HR (bpm) & $377 \pm 11$ & $379 \pm 9$ & $383 \pm 11$ & $407 \pm 11$ & $370 \pm 12$ & $387 \pm 6$ & $377 \pm 10$ & $391 \pm 6$ \\
\hline IVSd(mm) & $1.5 \pm 0.1$ & $0.9 \pm 0.1^{* *}$ & $1.0 \pm 0.01^{*}$ & $1.0 \pm 0.1^{*}$ & $1.6 \pm 0.1$ & $0.8 \pm 0.1^{* *}$ & $1.0 \pm 0.1^{*}$ & $0.8 \pm 0.1^{* *}$ \\
\hline LVIDd(mm) & $7.7 \pm 0.1$ & $8.3 \pm 0.3$ & $8.4 \pm 0.2$ & $8.1 \pm 0.3$ & $8.0 \pm 0.4$ & $10.1 \pm 0.3^{* *} \S$ & $9.7 \pm 0.4^{* *} \S$ & $9.7 \pm 0.2^{* *} \S$ \\
\hline LVPWd(mm) & $1.8 \pm 0.1$ & $1.8 \pm 0.1$ & $1.9 \pm 0.1$ & $1.8 \pm 0.1$ & $2.1 \pm 0.2$ & $2.3 \pm 0.2$ & $2.0 \pm 0.12$ & $2.0 \pm 0.1$ \\
\hline IVSs(mm) & $2.9 \pm 0.1$ & $1.3 \pm 0.2^{*}$ & $2.0 \pm 0.6$ & $1.3 \pm 0.2^{*}$ & $2.9 \pm 0.2$ & $1.0 \pm 0.2^{* *}$ & $1.2 \pm 0.2^{* *}$ & $1.2 \pm 0.2^{* *}$ \\
\hline LVIDs(mm) & $4.2 \pm 0.1$ & $6.5 \pm 0.3^{* *}$ & $6.0 \pm 0.4^{* *}$ & $6.3 \pm 0.3^{* *}$ & $4.6 \pm 0.4$ & $8.6 \pm 0.5^{* *} \S$ & $7.7 \pm 0.4^{* *}$ & $7.6 \pm 0.2^{* *} \S$ \\
\hline LVPWs(mm) & $2.9 \pm 0.1$ & $2.7 \pm 0.1$ & $2.6 \pm 0.2$ & $2.5 \pm 0.1$ & $2.9 \pm 0.2$ & $2.7 \pm 0.3$ & $2.6 \pm 0.1$ & $2.6 \pm 0.2$ \\
\hline LVEF (\%) & $82 \pm 1$ & $49 \pm 3^{* *}$ & $48 \pm 4^{* *}$ & $49 \pm 3^{* *}$ & $78 \pm 3$ & $36 \pm 5^{* *} \S$ & $45 \pm 5^{* *}$ & $48 \pm 4^{* *}$ \\
\hline FS (\%) & $46 \pm 2$ & $22 \pm 2^{* *}$ & $21 \pm 2^{* *}$ & $22 \pm 2^{* *}$ & $43 \pm 3$ & $16 \pm 3^{* *} \S$ & $21 \pm 2^{* *}$ & $22 \pm 2^{* *}$ \\
\hline
\end{tabular}

Data are presented as means \pm SEM; $N$ indicates number of animals; bpm, beats per minute. **P $<0.01$ and $* \mathrm{P}<0.05$ indicate significant differences compared to sham-operated rats in week 3 and week 12 respectively; $§ \mathrm{P}<0.05$ indicates significant difference between parameters at week 12 and week 3 using PairedSample T-Test. IVSd and IVSs, the thickness of the interventricular septum in diastole and systole; LVIDd and LVIDs, diastolic and systolic left ventricle dimensions; LVPWd and LVPWs, the thickness of left ventricle posterior wall in diastole and systole. 
Table 3 Hemodynamic parameters of the experimental groups at sacrifice (12 weeks).

\begin{tabular}{|c|c|c|c|c|}
\hline & $\begin{array}{l}\text { Sham } \\
\mathrm{N}=8\end{array}$ & $\begin{array}{c}\mathrm{MI} \\
\mathrm{N}=10\end{array}$ & $\begin{array}{l}\mathrm{MI}-\mathrm{VI} \\
\mathrm{N}=9\end{array}$ & $\begin{array}{l}\mathrm{MI}-\mathrm{VL} \\
\mathrm{N}=9\end{array}$ \\
\hline Heart rate (bpm) & $346 \pm 16$ & $378 \pm 7$ & $350 \pm 9$ & $361 \pm 12$ \\
\hline LVESP (mmHg) & $117 \pm 4$ & $109 \pm 3$ & $108 \pm 3$ & $109 \pm 4$ \\
\hline LVEDP (mmHg) & $6.2 \pm 0.8$ & $9.6 \pm 1.6^{*}$ & $9.8 \pm 1.3^{*}$ & $7.4 \pm 0.5$ \\
\hline $\mathrm{SBP}(\mathrm{mmHg})$ & $115 \pm 3$ & $111 \pm 2$ & $110 \pm 3$ & $113 \pm 3$ \\
\hline $\mathrm{DBP}(\mathrm{mmHg})$ & $87 \pm 2$ & $86 \pm 2$ & $85 \pm 2$ & $84 \pm 2$ \\
\hline dPdtmax (mmHg/s) & $8744 \pm 435$ & $7245 \pm 436$ & $6908 \pm 396$ & $7952 \pm 484$ \\
\hline dPdtmin $(\mathrm{mmHg} / \mathrm{s})$ & $-9363 \pm 268$ & $-6419 \pm 466^{*}$ & $-6592 \pm 613^{*}$ & $-7077 \pm 380^{*}$ \\
\hline
\end{tabular}

Data are presented as means \pm SEM; N indicates number of animals; LVESP, left ventricular end-systolic pressure; LVEDP, left ventricular end-diastolic pressure; $\mathrm{SBP}$, systolic blood pressure; DBP, diastolic blood pressure; $d P / d t m a x$ and $d P / d t m i n$, the maximal rate of increase and decrease of left ventricular pressure, respectively. ${ }^{*} \mathrm{P}<0.05$ vs. Sham.

attenuated in the vildagliptin-treated groups (Table 2). The LVEF in MI control group decreased from $49 \pm$ $3 \%$ at 3 weeks to $36 \pm 5 \%$ at 12 weeks, while in the early vildagliptin it decreased from $48 \pm 4 \%$ to $45 \pm$ $5 \%$, and in the late vildagliptin group from $49 \pm 3 \%$ to $48 \pm 4 \%$ (Table 2). The differences in LVEF at 12 weeks between the MI-control and the MI-vildagliptin groups were not significant. Thus, a significant worsening of LVEF was observed in the MI control group as compared to both vildagliptin groups.

Hemodynamic abnormalities were characteristic for rats with HF in the MI control group. Specifically, MI control rats showed significantly depressed dp/dtmax and elevated LVEDP compared with sham operated rats, while early and late vildagliptin treatment did not result in significant improvement (Table 3).

\section{Capillary density and cardiomyocyte size}

Capillary density was significantly reduced in all post-MI groups compared to sham-operated rats $(\mathrm{p}<0.01)$ (Figure 3). Cardiomyocyte size significantly increased in all post-MI groups compared to sham $(\mathrm{p}<0.01)$. Vildagliptin treatment both in early and late phase led to a trend towards diminished cardiomyocyte hypertrophy but no statistically significant effects were found compared to the MI control group ((Figure 4, $\mathrm{p}=\mathrm{NS}$ ).

\section{Cardiac gene expression}

ANP and BNP mRNA levels were significantly increased both in the MI control group as well in as late vildagliptin treatment group compared to sham group $(p<0.05)$. Vildagliptin treatment both in early and late phase had no significant effects herein (Figure 5A and 5B). Similar

\section{A $\quad$ B}

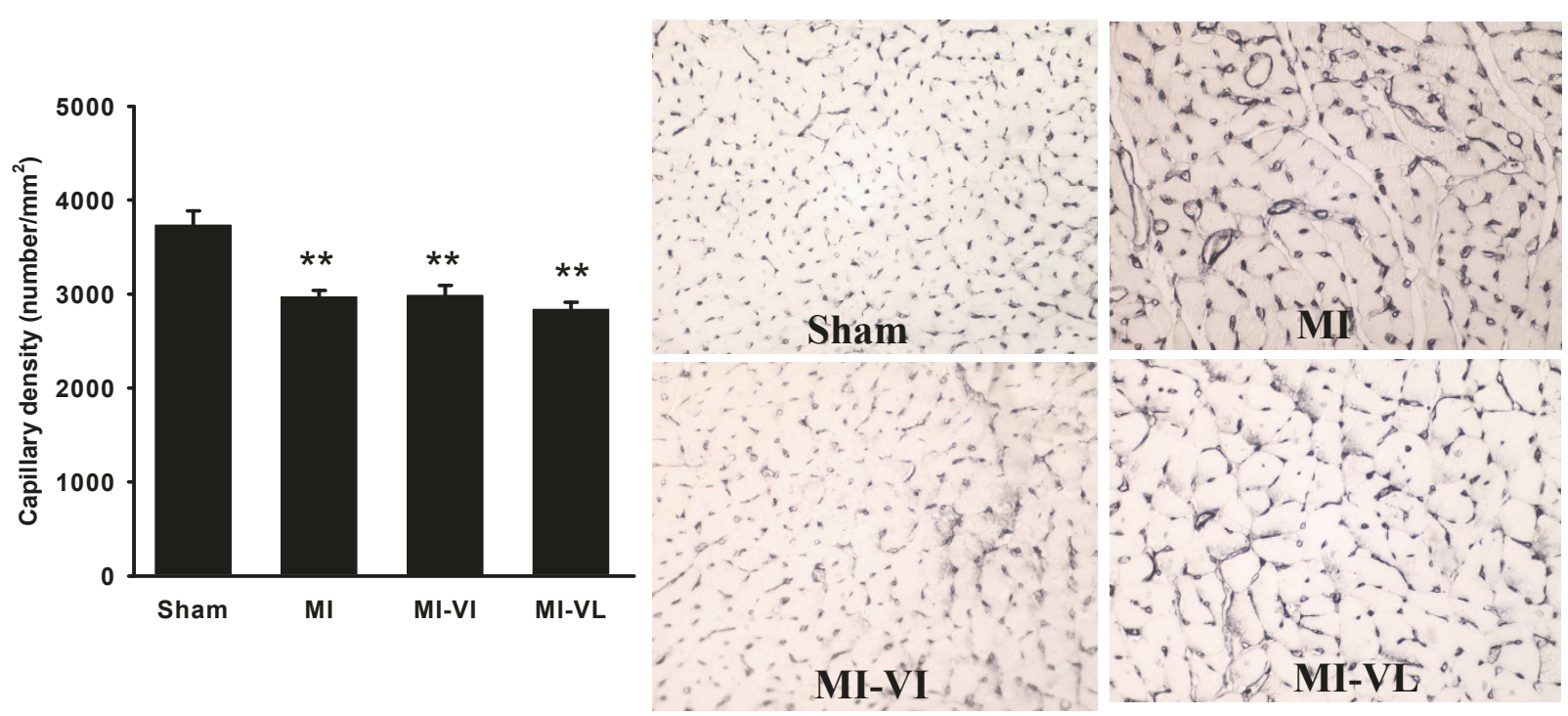

Figure 3 Effects of vildagliptin on capillary density in cardiomyocyte cross-sectional area. A: Graphic representation of capillary density expresses as the number of capillaries $/ \mathrm{mm}^{2}$ field. B: Typical examples of capillary density in the experimental groups at $\times 40$ magnification. Data are presented as means \pm SEM. $N=8-10$ for all groups. ${ }^{*} \mathrm{P}<0.01$ vs. sham group. 


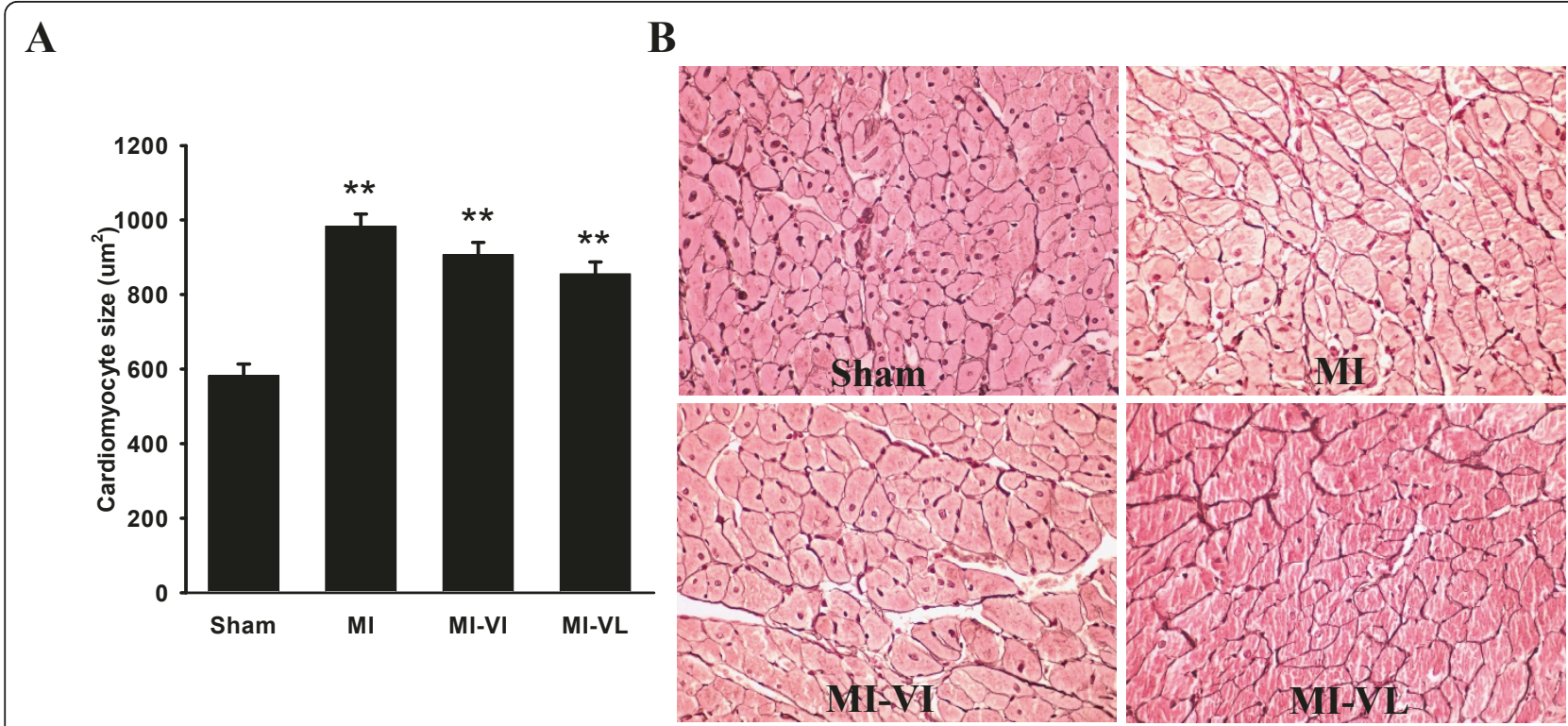

Figure 4 Cardiomyocyte size was measured by gomori staining in cross-sectional areas. A: Graphic representation of cardiomyocyte size in all experimental groups. B: Typical examples of cardiomyocyte size in the experimental groups at $\times 40$ magnification. Data are presented as means \pm SEM. $N=8-10$ for all groups. ${ }^{*}$ P $<0.01$ vs. sham group.

results were found for collagen I expression, which was significantly increased in the MI group compared to sham, while no difference was observed in collagen I expression between vildagliptin-treated groups and the control MI group (Figure 5C). MMP-9 mRNA levels were similar in all groups (Figure 5D).

\section{Discussion}

In the present study, we demonstrate that long-term treatment of the DPP-4 inhibitor vildagliptin in rats with $\mathrm{LV}$ remodeling due to $\mathrm{MI}$ increases endogenous active plasma GLP-1 levels, via inhibition of DPP-4 activity. However, this did not result in a decreased infarct size nor did it attenuate cardiac remodeling associated with post-MI. No differences in glucose levels and body weight were found in these non-diabetic rats when treated with vildagliptin.

To our knowledge, this is the first study to assess the effects of immediate and late vildagliptin treatment in a non-diabetic rat model. We furthermore aimed to dissect immediate versus late effects of DPP-4 inhibition. We herein show that neither early nor late vildagliptin treatments exert beneficial effects in MI-induced deterioration in cardiac remodeling. Notably, MI size was (non-significantly) smaller in the vildagliptin treated rats. However, this effect was observed both in rats immediately treated with vildagliptin as well as in rats in which treatment with vildagliptin started after 3 weeks, so when the infarction scar is fully organized. From this, we postulate that vildagliptin is unlikely to reduce infarct size. The associated differences in LVEF may be ascribed to the differences in infarct size. Other measures of LV remodeling were also unaffected by vildagliptin. For example, both early and late vildagliptin treatment did not reverse the MI-induced decrease in capillary density, measured at the border zone of the infarcted myocardium. Similarly, both early and late vildagliptin treatment did not counteract MI-induced cardiomyocyte hypertrophy. Furthermore, both early and late vildagliptin treatment had no effects on the MIinduced increases in cardiac expression of ANP, BNP. ANP and BNP cardiac gene expression closely associates with the severity of LV dysfunction [23], so this finding supports the notion that cardiac remodeling is not affected by vildagliptin. Furthermore, the expression of matricellular proteins collagen I and MMP-9 were also not affected by vildagliptin treatment.

A number of acute studies have been previously performed with DPP-4 inhibitors, GLP-1 or GLP-1 analogues, addressing their role in cardioprotection. A study with the DPP-4 inhibitor PFK275-055, a vildagliptinanalogue, showed a reduced infarct size with activation of the cardioprotective RISK (reperfusion-induced salvage kinase) pathway in pre-diabetic rats [24], whereas a study with the DPP-4 inhibitor sitagliptin showed that infarct size or short-term cardiac function were not affected by the treatment [25]. The latter study is in line with our study.

Another mean of increasing GLP-1 is direct GLP-1 infusion. Acute GLP-1 infusion studies both in patients 


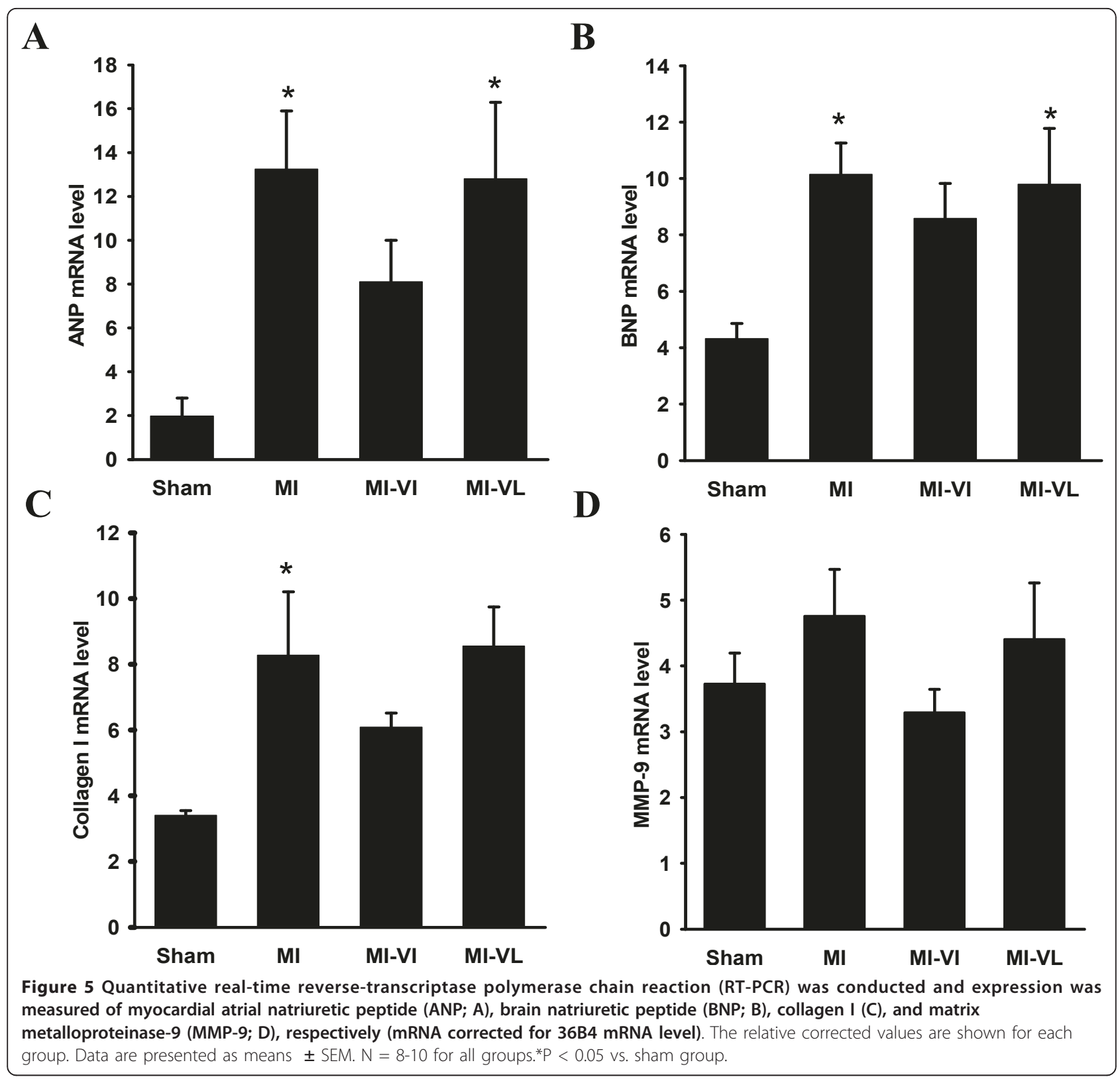

and rodents did show beneficial effects. In a clinical study, 3-day infusion of GLP-1 improved LV function in patients after acute MI [14]. Moreover, ischemia/reperfusion experiments in rats showed that GLP-1 administration prior to the ischemia leads to smaller infarct size in the isolated heart $[11,12,26]$. Another ischemia-reperfusion study showed that only the GLP-1 analogue exendin-4, but not GLP-1(9-36) amide exerts infarct-limiting action, while both of them improved LV performance [27]. Apparently, GLP-1 infusion provides a stronger effect than DPP-4 inhibition, probably due to a stronger elevation of GLP-1 levels. The published results from DPP-4 inhibition studies are variable and this might be explained by different levels of inhibition (different inhibitors used, different dosages), and variable levels of GLP-1.

So, although a number of acute studies have been performed, only few chronic studies have addressed the effects of GLP-1 on cardiac function in non-diabetic models. A chronic (3 month) infusion study showed that GLP-1 improved LV systolic function and prolonged survival in spontaneously hypertensive rats by increasing myocardial glucose uptake and reducing myocyte apoptosis [28]. Treatment with either GLP-1 or exenatide analogue AC3174 also demonstrated promising cardioprotective effects, including improved LVEF, 
LV end-diastolic pressure, and cardiac dimensions in a rat MI model (comparable to the present model) [29]. Our results are not in concert with the observations that cardioprotection is achieved by GLP-1 treatment. The reasons for the discrepancies between the present study and earlier work may be attributable to the dosing regimen, the different analogue utilized, the levels of GLP-1 achieved, and the timing of the treatment and the species studied [30].

Furthermore, a number of other issues should be considered when discussing the lack of vildagliptin-induced cardioprotection as observed in our study. First, we used a model of non-diabetic rats, with normal glucose levels. Vildagliptin is an antidiabetic agent which exerts its beneficial effects in the cardiovascular system through glycometabolic control. Thus it may be possible that vildagliptin is more beneficial in diabetic models. Second, as a DPP-4 inhibitor, vildagliptin inhibits degradation of GLP-1 and prolongs its half life in vivo; however, its effects are less strong than continuous GLP-1 infusion. The elevations in GLP-1 levels achieved by vildagliptin are likely to be lower than achieved by GLP-1 infusion and thus insufficient to produce cardioprotection. Finally, we do not know if other, hitherto unknown mechanisms, may underpin the effects of vildagliptin in the heart. To date, limited data are available describing the effects of vildagliptin on the cardiovascular system.

In addition, the biological effects of DPP-4 inhibitors appear different from GLP-1 and other GLP-1R agonists [31]. Vildagliptin treatment has no effect on body weight, food intake, energy expenditure and insulin sensitivity $[4,32,33]$. Although it has been shown that vildagliptin reduced plasma cholesterol and triglycerides in diabetic patients $[34,35]$, no effects of vildagliptin on these parameters were found in our post-MI animal study. However, GLP-1 inhibits glucagon secretion and controls body weight by decreasing food intake, increase insulin sensitivity and improve glucose uptake, which are beneficial cardiovascular factors [36-38]. Moreover, the protective effects of GLP-1 are also mediated through GLP-1R-independent pathways, partially though beneficial effects of its metabolite GLP-1 (9-36) [39]. These differences might explain why we observed only limited improvements in our study with vildagliptin as compared to other studies with GLP-1 and GLP-1 analogues.

\section{Limitations}

Possibly, the dosage of vildagliptin was not sufficient to observe a cardioprotective effect of vildagliptin. We did not include a group treated with GLP-1 infusion so we cannot compare DPP-4 inhibition to GLP-1. Furthermore, although plasma glucose was comparable in all groups, we did not assess factors associated with myocardial glucose metabolism, so that we cannot rule out if direct metabolic effects explain the results.

\section{Conclusions}

Long-term treatment with the DPP-4 inhibitor vildagliptin, started immediate or late after MI, does not preserve cardiac function in a rat post-MI remodeling model of chronic heart failure despite increases in plasma active GLP-1 levels by inhibiting DPP-4 activity.

\section{Acknowledgements}

Vildagliptin was kindly provided by Novartis (The Netherlands). M Yin is a recipient of a fellowship by the Graduate School for Drug Exploration (GUIDE) of the University of Groningen. Dr. de Boer is supported by the Netherlands Heart Foundation (grant 2007T046) and the Innovational Research Incentives Scheme program of the Netherlands Organization for Scientific Research (NWO VENI, grant 916.10.117).

\section{Authors' contributions}

MY carried out the animal experiments, the biomolecular studies and drafted the manuscript. HHWS performed molecular studies, and provided important intellectual input to the manuscript. MM performed statistical analysis and provided important intellectual input to the manuscript. WHvG conceived of the study and provided important intellectual input to the manuscript. RAdB conceived of the study, and participated in its design and coordination, and provided important intellectual input to the manuscript. All authors read and approved the final manuscript.

\section{Competing interests}

The authors declare that they have no competing interests.

Received: 20 July 2011 Accepted: 28 September 2011

Published: 28 September 2011

\section{References}

1. Nauck MA, Kleine N, Orskov C, Holst JJ, Willms B, Creutzfeldt W: Normalization of fasting hyperglycaemia by exogenous glucagon-like peptide 1 (7-36 amide) in type 2 (non-insulin-dependent) diabetic patients. Diabetologia 1993, 36(8):741-744.

2. Todd JF, Wilding JP, Edwards CM, Khan FA, Ghatei MA, Bloom SR: Glucagon-like peptide-1 (GLP-1): a trial of treatment in non-insulindependent diabetes mellitus. Eur J Clin Invest 1997, 27(6):533-536.

3. Zander M, Madsbad S, Madsen JL, Holst JJ: Effect of 6-week course of glucagon-like peptide 1 on glycaemic control, insulin sensitivity, and beta-cell function in type 2 diabetes: a parallel-group study. Lancet 2002, 359(9309):824-830.

4. Drucker DJ, Nauck MA: The incretin system: glucagon-like peptide-1 receptor agonists and dipeptidyl peptidase-4 inhibitors in type 2 diabetes. Lancet 2006, 368(9548):1696-1705.

5. Sokos GG, Nikolaidis LA, Mankad S, Elahi D, Shannon RP: Glucagon-like peptide-1 infusion improves left ventricular ejection fraction and functional status in patients with chronic heart failure. J Card Fail 2006, 12(9):694-699.

6. Bullock BP, Heller RS, Habener JF: Tissue distribution of messenger ribonucleic acid encoding the rat glucagon-like peptide-1 receptor. Endocrinology 1996, 137(7):2968-2978.

7. Nystrom T, Gutniak MK, Zhang Q, Zhang F, Holst JJ, Ahren B, Sjoholm A: Effects of glucagon-like peptide-1 on endothelial function in type 2 diabetes patients with stable coronary artery disease. Am J Physiol Endocrinol Metab 2004, 287(6):E1209-15.

8. Oeseburg $H$, de Boer RA, Buikema $H$, van der Harst $P$, van Gilst WH, Sillje HH: Glucagon-like peptide 1 prevents reactive oxygen speciesinduced endothelial cell senescence through the activation of protein kinase A. Arterioscler Thromb Vasc Biol 2010, 30(7):1407-1414.

9. Gros R, You X, Baggio LL, Kabir MG, Sadi AM, Mungrue IN, Parker TG, Huang Q, Drucker DJ, Husain M: Cardiac function in mice lacking the glucagon-like peptide-1 receptor. Endocrinology 2003, 144(6):2242-2252. 
10. Nikolaidis LA, Elahi D, Hentosz T, Doverspike A, Huerbin R, Zourelias L, Stolarski C, Shen YT, Shannon RP: Recombinant glucagon-like peptide-1 increases myocardial glucose uptake and improves left ventricular performance in conscious dogs with pacing-induced dilated cardiomyopathy. Circulation 2004, 110(8):955-961.

11. Bose AK, Mocanu MM, Carr RD, Yellon DM: Glucagon like peptide- 1 is protective against myocardial ischemia/reperfusion injury when given either as a preconditioning mimetic or at reperfusion in an isolated rat heart model. Cardiovasc Drugs Ther 2005, 19(1):9-11.

12. Bose AK, Mocanu MM, Carr RD, Brand CL, Yellon DM: Glucagon-like peptide 1 can directly protect the heart against ischemia/reperfusion injury. Diabetes 2005, 54(1):146-151.

13. Nikolaidis LA, Elahi D, Shen YT, Shannon RP: Active metabolite of GLP-1 mediates myocardial glucose uptake and improves left ventricular performance in conscious dogs with dilated cardiomyopathy. Am $J$ Physiol Heart Circ Physiol 2005, 289(6):H2401-8.

14. Nikolaidis LA, Mankad S, Sokos GG, Miske G, Shah A, Elahi D, Shannon RP: Effects of glucagon-like peptide- 1 in patients with acute myocardial infarction and left ventricular dysfunction after successful reperfusion. Circulation 2004, 109(8):962-965.

15. Deacon CF, Pridal L, Klarskov L, Olesen M, Holst JJ: Glucagon-like peptide 1 undergoes differential tissue-specific metabolism in the anesthetized pig. Am J Physiol 1996, 271(3 Pt 1):E458-64.

16. Bergman AJ, Stevens C, Zhou Y, Yi B, Laethem M, De Smet M, Snyder K, Hilliard D, Tanaka W, Zeng W, Tanen M, Wang AQ, Chen L, Winchell G, Davies MJ, Ramael S, Wagner JA, Herman GA: Pharmacokinetic and pharmacodynamic properties of multiple oral doses of sitagliptin, a dipeptidyl peptidase-IV inhibitor: a double-blind, randomized, placebocontrolled study in healthy male volunteers. Clin Ther 2006, 28(1):55-72.

17. Neumiller JJ, Campbell RK: Saxagliptin: a dipeptidyl peptidase-4 inhibitor for the treatment of type 2 diabetes mellitus. Am J Health Syst Pharm 2010, 67(18):1515-1525.

18. Verspohl EJ: Novel therapeutics for type 2 diabetes: incretin hormone mimetics (glucagon-like peptide-1 receptor agonists) and dipeptidyl peptidase-4 inhibitors. Pharmacol Ther 2009, 124(1):113-138.

19. Jin HY, Liu WJ, Park JH, Baek HS, Park TS: Effect of dipeptidyl peptidase-IV (DPP-IV) inhibitor (Vildagliptin) on peripheral nerves in streptozotocininduced diabetic rats. Arch Med Res 2009, 40(7):536-544.

20. Wang X, Zhang D, Xu W, Liu H, Wang W: Pharmacokinetics of lipoyl vildagliptin, a novel dipeptidyl peptidase IV inhibitor after oral administration in rats. Xenobiotica 2010, 40(10):707-712.

21. Yin M, van der Horst IC, van Melle JP, Qian C, van Gilst WH, Sillje HH, de Boer RA: Metformin improves cardiac function in a non-diabetic rat model of post-MI heart failure. Am J Physiol Heart Circ Physiol 2011

22. Westenbrink BD, Ruifrok WP, Voors AA, Tilton RG, van Veldhuisen DJ, Schoemaker RG, van Gilst WH, de Boer RA: Vascular endothelial growth factor is crucial for erythropoietin-induced improvement of cardiac function in heart failure. Cardiovasc Res 2010, 87(1):30-39.

23. de Boer RA, Henning RH, Suurmeijer AJ, Pinto YM, Olthof E, Kirkels JH, van Gilst WH, Crijns HJ, van Veldhuisen DJ: Early expression of natriuretic peptides and SERCA in mild heart failure: association with severity of the disease. Int J Cardiol 2001, 78(1):5-12.

24. Huisamen B, Genis A, Marais E, Lochner A: Pre-treatment with a DPP-4 inhibitor is infarct sparing in hearts from obese, pre-diabetic rats. Cardiovasc Drugs Ther 2011, 25(1):13-20.

25. Sauve M, Ban K, Momen MA, Zhou YQ, Henkelman RM, Husain M, Drucker DJ: Genetic deletion or pharmacological inhibition of dipeptidyl peptidase-4 improves cardiovascular outcomes after myocardial infarction in mice. Diabetes 2010, 59(4):1063-1073.

26. Bose AK, Mocanu MM, Carr RD, Yellon DM: Myocardial ischaemiareperfusion injury is attenuated by intact glucagon like peptide-1 (GLP1 ) in the in vitro rat heart and may involve the p70s6K pathway. Cardiovasc Drugs Ther 2007, 21(4):253-256.

27. Sonne DP, Engstrom T, Treiman M: Protective effects of GLP-1 analogues exendin-4 and GLP-1(9-36) amide against ischemia-reperfusion injury in rat heart. Regul Pept 2008, 146(1-3):243-249.

28. Poornima I, Brown SB, Bhashyam S, Parikh P, Bolukoglu H, Shannon RP: Chronic glucagon-like peptide-1 infusion sustains left ventricular systolic function and prolongs survival in the spontaneously hypertensive, heart failure-prone rat. Circ Heart Fail 2008, 1(3):153-160.
29. Liu Q, Anderson C, Broyde A, Polizzi C, Fernandez R, Baron A, Parkes DG: Glucagon-like peptide-1 and the exenatide analogue AC3174 improve cardiac function, cardiac remodeling, and survival in rats with chronic heart failure. Cardiovasc Diabetol 2010, 9:76.

30. Anagnostis P, Athyros VG, Adamidou F, Panagiotou A, Kita M, Karagiannis A, Mikhailidis DP: Glucagon-like peptide-1-based therapies and cardiovascular disease: looking beyond glycaemic control. Diabetes Obes Metab 2011, 13(4):302-312.

31. Doupis J, Veves A: DPP4 inhibitors: a new approach in diabetes treatment. Adv Ther 2008, 25(7):627-643.

32. Flock $G$, Baggio LL, Longuet $C$, Drucker DJ: Incretin receptors for glucagon-like peptide 1 and glucose-dependent insulinotropic polypeptide are essential for the sustained metabolic actions of vildagliptin in mice. Diabetes 2007, 56(12):3006-3013.

33. Vella $A$, Bock G, Giesler PD, Burton DB, Serra DB, Saylan ML, Dunning BE, Foley JE, Rizza RA, Camilleri M: Effects of dipeptidyl peptidase-4 inhibition on gastrointestinal function, meal appearance, and glucose metabolism in type 2 diabetes. Diabetes 2007, 56(5):1475-1480.

34. Matikainen N, Manttari S, Schweizer A, Ulvestad A, Mills D, Dunning BE, Foley JE, Taskinen MR: Vildagliptin therapy reduces postprandial intestinal triglyceride-rich lipoprotein particles in patients with type 2 diabetes. Diabetologia 2006, 49(9):2049-2057.

35. Rosenstock J, Baron MA, Dejager S, Mills D, Schweizer A: Comparison of vildagliptin and rosiglitazone monotherapy in patients with type 2 diabetes: a 24-week, double-blind, randomized trial. Diabetes Care 2007, 30(2):217-223.

36. Drucker DJ: The biology of incretin hormones. Cell Metab 2006, 3(3):153-165

37. Kurukulasuriya LR, Sowers JR: Therapies for type 2 diabetes: lowering $\mathrm{HbA1c}$ and associated cardiovascular risk factors. Cardiovasc Diabetol 2010, 9:45.

38. Fisman EZ, Tenenbaum A: A cardiologic approach to non-insulin antidiabetic pharmacotherapy in patients with heart disease. Cardiovasc Diabetol 2009, 8:38.

39. Ban K, Noyan-Ashraf MH, Hoefer J, Bolz SS, Drucker DJ, Husain M: Cardioprotective and vasodilatory actions of glucagon-like peptide 1 receptor are mediated through both glucagon-like peptide 1 receptordependent and -independent pathways. Circulation 2008 117(18):2340-2350

doi:10.1186/1475-2840-10-85

Cite this article as: Yin et al.: Early and late effects of the DPP-4 inhibitor vildagliptin in a rat model of post-myocardial infarction heart failure. Cardiovascular Diabetology 2011 10:85.

\section{Submit your next manuscript to BioMed Central and take full advantage of:}

- Convenient online submission

- Thorough peer review

- No space constraints or color figure charges

- Immediate publication on acceptance

- Inclusion in PubMed, CAS, Scopus and Google Scholar

- Research which is freely available for redistribution 